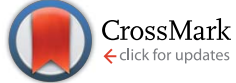

Cite this: RSC Adv., 2015, 5, 23383

Received 27th November 2014 Accepted 16th February 2015

\section{Effect of surfactant on bound water content and extracellular polymers substances distribution in sludge}

\author{
Chen Hong, ${ }^{\text {ab }}$ Yanxiao Si, ${ }^{a}$ Yi Xing, ${ }^{* a}$ ZhiQiang Wang, ${ }^{a}$ Qeng Qiao*ac and Min Liu ${ }^{a}$
}

DOI: $10.1039 / c 4 r a 15370 \mathrm{~g}$

www.rsc.org/advances

In this study, the effect of surfactant conditioning on bound water and extracellular polymers substances (EPS) in sludge was investigated. Results showed that by adding dodecyl dimethyl benzyl ammonium chloride (DDBAC), loosely bound EPS (LB-EPS) and slime layer EPS (S-EPS) contents were increased, while tightly bound EPS (TB-EPS) and bound water contents $\left(W_{\mathrm{B}}\right)$ were reduced. As a result, the dewatering performance of sludge was enhanced. When $75 \mathrm{mg} \mathrm{g}^{-1}$ of DDBAC were added, $W_{\mathrm{B}}$ in sludge decreased to $1.64 \mathrm{~g} \mathrm{~g}^{-1}$, and the water content of dewatered sludge $\left(W_{C}\right)$ dropped to $66.61 \%$. EPS partially hydrolyzed into small molecular organics under DDBAC conditioning. Moreover, the quantity and species of organic functional groups in SEPS were increased obviously. The TB-EPS content accounted for the majority of EPS in sludge, and the protein and polysaccharide in TBEPS had a significant positive correlation with bound water, which was the main factor affecting $W_{\mathrm{B}}$ in sludge.

\section{Introduction}

In municipal sewage treatment plants, the moisture content of sludge is typically over $95 \%$. Sludge dewatering is the most significant process among sewage treatments in sludge reduction, harmless treatment and reutilization. ${ }^{1,2}$ However, urban sewage sludge is rich in organic substances, which leads to the formation of colloidal structure in sludge floc particles. These particles are very hydrophilic, as they effortlessly combine with water molecules in different manner. Thus, they make it difficult to remove this part of water from sludge. ${ }^{3}$ A more detailed classification of water distribution in sludge can be divided into four types of patterns, namely, free water, pore water, adsorbed

${ }^{a}$ Department of Environmental Engineering, University of Science and Technology Beijing, Xueyuan Road No. 30, Haidian District, Beijing, 100083, P. R. China. E-mail: xingyi@ustb.edu.cn; alanxy3000@gmail.com; Tel: +8601062332206

${ }^{b}$ Research Centre for Eco-Environmental Sciences, Chinese Academy Science, Shuangqing Road No. 18, Haidian District, Beijing, 100085, P. R. China

${ }^{c}$ School of Chemical Engineering, University of Birmingham, Edgbaston, Birmingham, B15 2TT, UK water, and bound water. ${ }^{4}$ However, this division has currently no quantitative measurements. Moisture is usually divided into free and bound types of water through usual quantitative methods. ${ }^{5}$ Free water is not restrained by sludge floc bondage, but it can be separated from sludge through concentration or mechanical dewatering. Moreover, bound water has a strong bond with sludge flocs. It is specifically tightly restrained in sludge and it is difficult to remove through mechanical force. ${ }^{6}$

The presence of bound water has a close relationship with extracellular polymers substances (EPS) in sludge. EPS is an insoluble organic matter attached to the surface of the sludge bacterial cell, which is the third largest composition in addition to bacterial cells and water. ${ }^{7}$ EPS accounts for $50 \%$ to $90 \%$ of total organic matter in activated sludge, and it can stabilize sludge floc structures by connecting microbial cells and other substances. ${ }^{8}$ EPS binds water to the solid surfaces or capture water inside the cells or flocs because of its strong water binding. capacity. ${ }^{9-11}$ Thus, EPS is a key factor affecting the stability and dewatering of sludge. ${ }^{12}$ The main components of EPS are proteins and polysaccharides, which account for $70 \%$ to $80 \%$ of total EPS. ${ }^{13,14}$ According to the combination degree between organic matter and sludge flocs, EPS can be divided into slime layer EPS (S-EPS), loosely bound EPS (LB-EPS), and tightly bound EPS (TB-EPS). ${ }^{15}$ Jin et al. ${ }^{6}$ argued that the polymeric component such as proteins and carbohydrates significantly contribute to improve the water binding ability of sludge flocs.

In studies of sludge dewatering, numerous researchers concluded that adding surfactants could improve sludge dewatering performance. ${ }^{16-20}$ Chen et al. ${ }^{16}$ reported that in addition to the enhancement of the ability to demolish the sludge structure, the dissolution of suspended solids and digestion of extracellular components could be enhanced by the introduction of a surfactant (lauryl betaine), compared to traditional sludge conditioner $\left(\mathrm{FeCl}_{3}, \mathrm{CaO}\right)$. Furthermore, the protein and carbohydrate concentrations in the sludge liquid increased, and the dewatering and filtering performance were also enhanced. Yuan et al..$^{20}$ used electrolysis and surfactant joint conditioning sludge in their study. The results demonstrated that adding 
surfactant helped to increase the concentration of S-EPS, reduce viscosity and zeta potential of the sludge, and improve the sewage sludge dewatering performance. Current studies focus on the relationship between the S-EPS content and the sludge dewatering performance under surfactant conditioning. The effect of surfactant on LB-EPS and TB-EPS, and the relation between EPS layers (S-EPS, LB-EPS, and TB-EPS) and bound water under surfactant conditioning is not well known yet.

The effect of surfactant (dodecyl dimethyl benzyl ammonium chloride, DDBAC) conditioning on EPS and bound water in sludge was investigated in this study. The impact of surfactant on dewatered sludge water content, bound water content, the content of protein and polysaccharide in different EPS layers, and the relation between bound water content and EPS distribution were analyzed. Fourier transform infrared spectroscopy (FTIR) and high-performance liquid chromatography (HPLC) were used to test sludge supernatant to demonstrate the changes in organic matter in quantity and variety. The aim is to provide a more comprehensive study on the sludge dewatering mechanism under surfactant conditioning.

\section{Materials and methods}

\subsection{Materials}

The sludge used in this study was collected from the sludge concentration tank in Xiaohongmen sewage treatment plant, Beijing. It was dewatered to $95 \%$ in terms of water content before being employed as test sample. The properties of the sludge before conditioning in this study are shown in Table 1. All the experiments were completed within $48 \mathrm{~h}$ and the sludge was placed in a freezer at $4{ }^{\circ} \mathrm{C}$ beforehand.

Sludge conditioner is a cationic surfactant (dodecyl dimethyl benzyl ammonium chloride, DDBAC), with a chemical formula $\mathrm{C}_{21} \mathrm{H}_{38} \mathrm{NCl}$ and has a relative molecular mass of 340.00 .

\subsection{Experimental methods}

2.2.1 Surfactant conditioning sludge. Different portions of DDBAC were added in $100 \mathrm{~mL}$ sludge in a $150 \mathrm{~mL}$ beaker. The mixture was stirred for $10 \mathrm{~min}$ at a frequency of $100 \mathrm{rpm}$, and then was left static for $30 \mathrm{~min}$. After conditioning, $50 \mathrm{~mL}$ sludge was placed into a Büchner funnel with $150 \mathrm{~nm}$ of diameter. Filtration followed by dehydration under a vacuum pressure of

Table 1 Properties of sludge used in this study before conditioning

\begin{tabular}{llll}
\hline Parameters & & Units & Value \\
\hline TSS & & $\mathrm{mg} \mathrm{L}^{-1}$ & $48952.55 \pm 244.78$ \\
VSS & $\mathrm{mg} \mathrm{L}^{-1}$ & $32843.52 \pm 1644.26$ \\
pH value & - & $7.19 \pm 0.12$ \\
Water content & $\%$ & $95.07 \pm 0.15$ \\
Bound water & & $\mathrm{g} \mathrm{g}^{-1}$ & $3.24 \pm 0.26$ \\
S-EPS & Protein & $\mathrm{mg} \mathrm{L}^{-1}$ & $363.31 \pm 18.23$ \\
& Polysaccharide & $\mathrm{mg} \mathrm{L}^{-1}$ & $72.68 \pm 6.74$ \\
LB-EPS & Protein & $\mathrm{mg} \mathrm{L}^{-1}$ & $143.16 \pm 7.57$ \\
& Polysaccharide & $\mathrm{mg} \mathrm{L}^{-1}$ & $29.06 \pm 3.34$ \\
TB-EPS & Protein & $\mathrm{mg} \mathrm{L}^{-1}$ & $3045.02 \pm 150.46$ \\
& Polysaccharide & $\mathrm{mg} \mathrm{L}^{-1}$ & $602.54 \pm 33.52$
\end{tabular}

$-0.055 \mathrm{MPa}$ was then conducted. The filtration dehydration was complete when the filtrate flow was absent for $30 \mathrm{~s}$.

2.2.2 Water content. Sludge dewaterability was evaluated in terms of the water content in dewatered sludge $\left(W_{\mathrm{C}}\right)$. The $W_{\mathrm{C}}$ was calculated as follows:

$$
W_{\mathrm{C}}=\frac{W_{1}-W_{2}}{W_{1}-W_{\mathrm{DDBAC}}} \times 100 \%
$$

where $W_{1}$ is the weight of dewatered sludge and $W_{2}$ is the weight of dewatered sludge under $105{ }^{\circ} \mathrm{C}$ drying to constant weight, and $W_{\text {DDBAC }}$ is the weight of DDBAC adsorbed on dewatered sludge.

2.2.3 Bound water content. Bound water content $\left(W_{\mathrm{B}}\right)$ was measured by a differential scanning calorimetry (DSC) method. ${ }^{21}$ With a certain amount of dewatered sludge in the DSC analyzer (NETZSCH, 404 F3 Pegasus, Germany), sludge samples were cooled down to $-30{ }^{\circ} \mathrm{C}$ at a rate of $5{ }^{\circ} \mathrm{C} \mathrm{min}{ }^{-1}$, and then warmed up to room temperature at the same rate. Theoretically, samples would release heat and show a significant exothermic peak in the process of freezing and present a clear endothermic peak at heating stage. Because bound water does not freeze at $-30{ }^{\circ} \mathrm{C}$, heat released during the measurements reflected free water content in the sludge. $W_{\mathrm{B}}$ is the difference between total water content and free water content. The formula is as follows:

$$
W_{\mathrm{B}}=\frac{W_{\mathrm{T}}-\Delta H / \Delta H_{0}}{W_{\mathrm{DS}}-W_{\mathrm{DDBAC}}}
$$

where $W_{\mathrm{T}}$ is total water content of sample, $\Delta H$ is DSC endothermic of sample, $W_{\mathrm{DS}}$ is the weight of dry sludge in sample, and $\Delta H_{0}$ is the standard fusion heat of ice, $334.7 \mathrm{~J} \mathrm{~g}^{-1}$.

2.2.4 EPS extraction and determination. EPS were extracted via centrifugation and ultrasonication. ${ }^{22} 30 \mathrm{~mL}$ sludge after conditioning were centrifuged for $15 \mathrm{~min}$ at $3000 \mathrm{rpm}$. The collected supernatant was considered to be S-EPS. The precipitate was diluted into its original volume $(30 \mathrm{~mL})$ with deionized water and centrifuged for $15 \mathrm{~min}$ at $7400 \mathrm{rpm}$. Then, the supernatant was filtered through a $0.45 \mu \mathrm{m}$ membrane. Organics in solution were considered to be LB-EPS. The sediment left was then diluted again into the original volume (30 $\mathrm{mL}$ ) with deionized water, and then it was ultrasonicated (20 $\mathrm{kHz}, 480 \mathrm{~W}, 10 \mathrm{~min}$ ) before centrifugation (20 min and 15000 $\mathrm{rpm})$. The supernatant was filtered through a $0.45 \mu \mathrm{m}$ membrane, in which the residual organics in the filtrate were regarded as TB-EPS.

The Folin-phenol (Lowry) method was employed to determine the extracellular protein content, and an anthrone colorimetric method was used to measure the polysaccharide content. $^{23,24}$

2.2.5 FTIR study. S-EPS were freeze-dried to observe the organic functional groups by freeze-drier (FDU-1100, Eyela, Japan). The residual solid was compressed via $\mathrm{KBr}$, and then determined using a Fourier transform infrared spectrometer (FTIR) (IR-408, Shimadzu, Japan).

2.2.6 HPLC study. (1) The content of DDBAC in sludge filtrate was determined by high performance liquid chromatography (HPLC) (LC-20AD, Shimadzu, Japan), and the 
absorption amount of DDBAC in sludge was calculated as the DDBAC dosage minus the DDBAC content in the sludge filtrate.

Chromatography was employed under the following conditions: the mobile phase was $90 \% \mathrm{CH}_{3} \mathrm{CN}-0.10 \mathrm{~mol} \mathrm{~L}^{-1}$ $\mathrm{CH}_{3} \mathrm{COONH}_{4}$ solution (v/v) filtered through a $0.45 \mu \mathrm{m}$ membrane, and then degassed by ultrasonication for $10 \mathrm{~min}$. The flow rate was $0.5 \mathrm{~mL} \mathrm{~min}^{-1}$, column temperature was $25 \pm$ $1{ }^{\circ} \mathrm{C}$, measurement wavelength was $262 \mathrm{~nm}$, injection volume was $20 \mu \mathrm{L}$, and the high peaks were quantified via the external standard method.

(2) Organic matter hydrolysis in sludge supernatant was analyzed by liquid chromatography. HPLC was applied to determine the content of small molecular organic acids (formic acid, acetic acid, and propionic acid). Liquid chromatography could measure the organic compounds hydrolysis.

Chromatographies were performed under the following conditions: the mobile phase was $7 \% \mathrm{CH}_{3} \mathrm{OH}-0.20 \mathrm{~mol} \mathrm{~L}^{-1}$ $\mathrm{KH}_{2} \mathrm{PO}_{4}(\mathrm{pH}=4.0)$ buffer solution (v/v) filtered through a 0.45 $\mu \mathrm{m}$ membrane, and then degassed by ultrasonication for 10 min. The flow rate was $0.5 \mathrm{~mL} \mathrm{~min}^{-1}$, column temperature was $40 \pm 1{ }^{\circ} \mathrm{C}$, measurement wavelength was $215 \mathrm{~nm}$, the injection volume was $20 \mu \mathrm{L}$, and the high peaks were quantified via the external standard method.

\section{Results and discussion}

\subsection{Changes of $W_{\mathrm{C}}$ and composition in dewatered sludge after conditioning with surfactant DDBAC}

As shown in Fig. 1, the dewatering performance of sludge under conditioning significantly improved when the surfactant (DDBAC) dosage was increased. $W_{\mathrm{C}}$ decreased from $79.36 \%$ (DDBAC dosage was $0 \mathrm{mg} \mathrm{g}^{-1}, \mathrm{mg} \mathrm{g}^{-1}$ indicated DDBAC dosage per gram of dry sludge in the sample, similarly hereinafter) to $62.95 \%$ (DDBAC dosage was $150 \mathrm{mg} \mathrm{g}^{-1}$ ), indicating a $16.41 \%$ decline. When the DDBAC dosage increased from $56.25 \mathrm{mg} \mathrm{g}^{-1}$ to $75 \mathrm{mg} \mathrm{g}^{-1}, W_{\mathrm{C}}$ significantly decreased from $72.05 \%$ to $66.61 \%$, representing a $5.44 \%$ decline. Moreover, when the DDBAC dosage was greater than $75.00 \mathrm{mg} \mathrm{g}^{-1}$, the downward trend of $W_{\mathrm{C}}$ slowed down. These results were in agreement with Chen et al. ${ }^{16}$ and Yuan et al. ${ }^{20}$ who observed similar results in sludge dewatering performance, improving significantly under surfactants conditions.

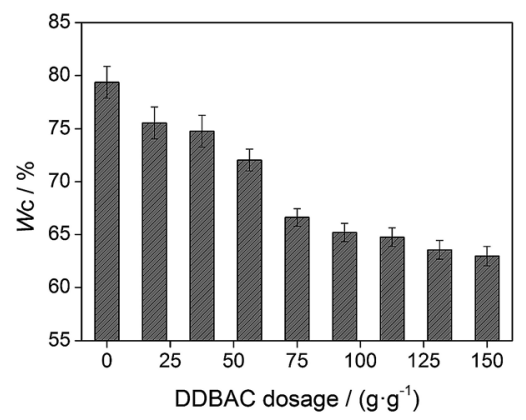

Fig. $1 W_{C}$ of dewatered sludge after DDBAC conditioning.
The decreasing trend of $W_{\mathrm{C}}$ was due to the reduction of $W_{\mathrm{B}}$. $W_{\mathrm{B}}$ was held firmly in the floc matrix, bound to the sludge or trapped between sludge particles and could not be removed by mechanical methods. This was considered to be the limit of mechanical dewatering. According to Colin and Gazbar, ${ }^{25} W_{\mathrm{B}}$ could be used to directly measure the difficulty degree of mechanical dewatering. More bound water resulted in more difficult mechanical dewatering, whereas less bound water resulted in easier mechanical dewatering. The $W_{\mathrm{B}}$ under conditioning with surfactant DDBAC is presented in Fig. 2(a). Addition of DDBAC could significantly reduce $W_{\mathrm{B}}$. When the DDBAC dosage increased from $0 \mathrm{mg} \mathrm{g}^{-1}$ to $75 \mathrm{mg} \mathrm{g}^{-1}, W_{\mathrm{B}}$ quickly decreased from $3.24 \mathrm{~g} \mathrm{~g}^{-1}\left(\mathrm{~g} \mathrm{~g}^{-1}\right.$ indicated $W_{\mathrm{B}}$ per gram of dry sludge in sample, similarly hereinafter) to $1.64 \mathrm{~g} \mathrm{~g}^{-1}$, indicating a drop of $49.38 \%$. When the DDBAC dosage was continuously increased, the decreasing trend of $W_{\mathrm{B}}$ slowed down. $W_{\mathrm{B}}$ and $W_{\mathrm{C}}$ were ramping down in a similar trend (Fig. 1 and 2(a)). These results indicated that the introduction of DDBAC was beneficial to release bound water from sludge, and then caused the decrease of $W_{\mathrm{C}}$. Eventually, when the DDBAC dosage was $150 \mathrm{mg} \mathrm{g}^{-1}, W_{\mathrm{B}}$ reduced to $1.36 \mathrm{~g} \mathrm{~g}^{-1}$, representing a $58.02 \%$ decline. These findings were in agreement with a research reported by Wang et $a .^{26}$ who observed that the surfactant effectively released bound water from sludge, due to its superior surface activity and strong adsorption/bridge capacities with sludge.

Approximately $42 \%$ of bound water in sludge could not be released. A reasonable explanation was that this part of bound water combined with sludge flocs through a considerably strong chemically/physically bond, and was not easily influenced by DDBAC or released into the liquid phase.
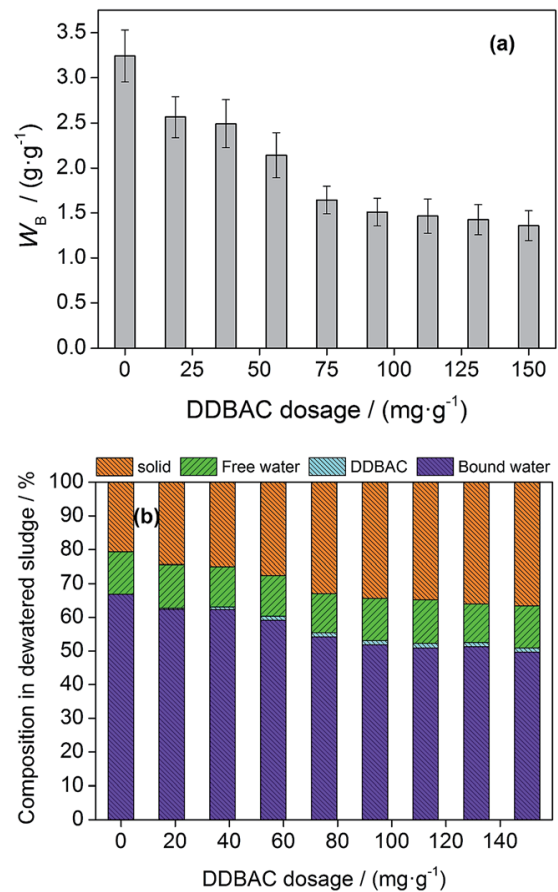

Fig. $2 W_{\mathrm{B}}$ and composition distribution of dewatered sludge: (a) $W_{\mathrm{B}}$; (b) composition in dewatered sludge. 
Relative proportions of solid, bound and free water in dewatered sludge obviously changed after conditioning with DDBAC, as shown in Fig. 2(b). After conditioning with DDBAC, the proportion of bound water in sludge cake significantly decreases from $66.87 \%$ (unconditioned sludge cake) to $49.69 \%$ (DDBAC dosage was $150 \mathrm{mg} \mathrm{g}^{-1}$ ), and the proportion of solid increases from $20.64 \%$ to $36.58 \%$. $W_{\mathrm{B}}$ was considered as a critical factor for the sludge dewatering performance. The surfactant DDBAC conditioning did not only significantly reduce $W_{\mathrm{B}}$ and $W_{\mathrm{C}}$, but also increased the total solid proportion in the dewatered sludge. The proportion of free water in the sludge cake changed slightly and remained between $11 \%$ and $13 \%$, which indicated the presence of free water in the sludge cake. This happened because the mechanical strength in the dehydration process was not enough to remove the free water. The removal rate of free water by mechanical force depended on the mechanical dewatering device and had no correlation with sludge conditioning.

\subsection{Effect of EPS on bound water under the surfactant DDBAC conditions}

3.2.1. Changes in EPS content and DDBAC adsorption amounts in sludge. EPS was thought to be one of the most important factors affecting sludge dewaterability. ${ }^{27-30}$ The protein and carbohydrate components of EPS had a significant contribution to enhance the water binding ability of the sludge flocs. ${ }^{6}$ Analyzing the change of each layer of EPS in sludge could help to clarify the mechanism of bound water release under surfactant conditioning. The distribution and changes of protein and polysaccharide portions in sludge under surfactant DDBAC conditioning are shown in Fig. 3. Protein and polysaccharide in the original sludge were mainly distributed in the
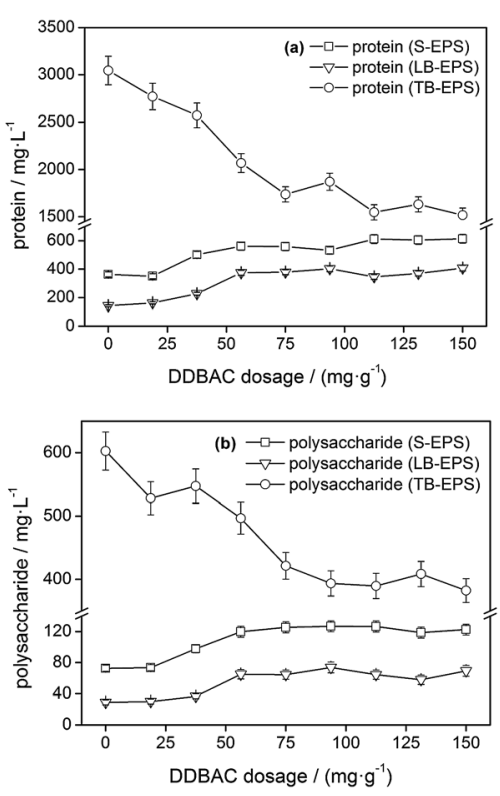

Fig. 3 Changes of EPS in sludge: (a) distributions and changes of protein in EPS layers; (b) distributions and changes of polysaccharide in EPS layers.
TB-EPS, accounting for $85.74 \%$ of total protein and $85.55 \%$ of total polysaccharide. In the LB-EPS, protein accounted for $4.03 \%$ and polysaccharide for $4.12 \%$. In the S-EPS, protein and polysaccharide accounted for $10.23 \%$ and $10.32 \%$, respectively. In the original sludge, the distribution of protein and polysaccharide in every EPS layer was different. They were mainly distributed in the TB-EPS, and were less distributed in both the LB-EPS and S-EPS. Wang ${ }^{31}$ have also obtained similar results, showing that more than $80 \%$ of the EPS was TB-EPS.

After conditioning with surfactant DDBAC, protein and polysaccharide contents in EPS layers obviously changed. These contents in TB-EPS were decreased by adding DDBAC. When the DDBAC dosage was $75 \mathrm{mg} \mathrm{g}^{-1}$, the content of protein in TB-EPS droped to $1737 \mathrm{mg} \mathrm{L}^{-1}$, when it was $3045 \mathrm{mg} \mathrm{L}^{-1}$ beforehand, and the polysaccharide content changed from $602 \mathrm{mg} \mathrm{L}^{-1}$ to $421 \mathrm{mg} \mathrm{L}^{-1}$, indicating a decrease of $42.96 \%$ and $30.07 \%$, respectively. When the DDBAC dosage continued to increase, the decreasing rate of protein and polysaccharide contents in the TB-EPS slowed down. On the contrary, the introduction of DDBAC caused these contents to increase in LB-EPS and S-EPS. When the DDBAC dosage was $75 \mathrm{mg} \mathrm{g}^{-1}$, the protein content in LB-EPS increased from $143 \mathrm{mg} \mathrm{L}^{-1}$ to $374 \mathrm{mg} \mathrm{L}{ }^{-1}$, and the polysaccharide content increased from $29 \mathrm{mg} \mathrm{L}^{-1}$ to $65 \mathrm{mg} \mathrm{L}^{-1}$, accounting for increases of $161.54 \%$ and $124.14 \%$, respectively. At the same time, the protein and polysaccharide contents in SEPS increased from $363 \mathrm{mg} \mathrm{L}^{-1}$ to $561 \mathrm{mg} \mathrm{L}^{-1}$ and from $73 \mathrm{mg}$ $\mathrm{L}^{-1}$ to $120 \mathrm{mg} \mathrm{L}^{-1}$, accounting for increases of $54.55 \%$ and $64.38 \%$, respectively. These results were in accordance with Chen et al. ${ }^{16}$ and Yuan et al. studies. ${ }^{30}$ They observed that the EPS content of sludge supernatant (corresponding to S-EPS) increased with the increasing surfactant. When the surfactant DDBAC dosage was more than $75 \mathrm{mg} \mathrm{g}^{-1}$, it had a less significant effect on protein and polysaccharide contents in the LBEPS and S-EPS.

The surfactant DDBAC can help in dispersing sludge folcs and dissolving organic matters. The binding effect of sludge flocs on the TB-EPS and LB-EPS is weakened by adding the surfactant. Therefore, parts of TB-EPS could turn into LB-EPS or S-EPS, and LB-EPS could turn into S-EPS. Moreover, insoluble EPS (TB-EPS and LB-EPS), which had high hydration ability, can be turned into soluble EPS (S-EPS). Soluble EPS left the sludge flocs surface and easily entered the sludge liquid phase. Thus, bound water previously combined with EPS was released and turned to free water, and therefore, the sludge dewatering performance could be improved. This process was in accordance with the decrease in TB-EPS content, increase in LB-EPS and S-EPS contents, and decline of $W_{\mathrm{B}}$ under DDBAC conditioning (Fig. 2 and 3). Similar conclusions were reached by $\mathrm{S}$. Kavitha ${ }^{32}$ and Huang, ${ }^{33}$ whose results indicated that surfactants could not only efficiently disperse sludge flocs, but are also beneficial to solubilize organic matters.

The adsorption amounts of DDBAC in sludge are illustrated by Fig. 4. The adsorption process between EPS and surfactant was influenced by both electrostatic effect and hydrophobic effect. ${ }^{34}$ Under these two effects, EPS was desquamated from sludge flocs, and DDBAC got into the sludge liquid-phase with peeled LB-/TB-EPS. The adsorption amounts of DDBAC in 


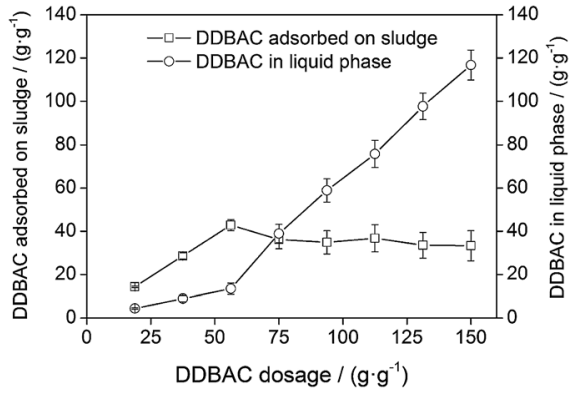

Fig. 4 Adsorption amounts of DDBAC in sludge.

sludge first increased and then decreased. When the DDBAC dosage was $56.25 \mathrm{mg} \mathrm{g}^{-1}$, the maximum adsorption amounts of DDBAC could be obtained was $42.82 \mathrm{mg} \mathrm{g}^{-1}$. Then, the adsorption amounts of DDBAC decreased to $36.13 \mathrm{mg} \mathrm{g}^{-1}$ when the DDBAC dosage increased to $75 \mathrm{mg} \mathrm{g}^{-1}$. With the continuous increase in DDBAC dosage, the DDBAC adsorption amounts plateaued, and the alterations of $W_{\mathrm{B}}$ and EPS became small, indicating that the conditioning effect of DDBAC on sludge weakened (Fig. 2 and 3). Therefore, $75 \mathrm{mg} \mathrm{g}^{-1}$ was considered to be the optimal dosage of DDBAC.

3.2.2. Effect of EPS on $\boldsymbol{W}_{\mathrm{B}}$. The amount of EPS was positively correlated with bound water. The correlation between $W_{\mathrm{B}}$ and protein, as well as polysaccharide contents in EPS layers are presented in Fig. 5 and Table 2. Linear regression and Pearson correlation indicated that protein and polysaccharide contents in the S-EPS had significant negative correlation with $W_{\mathrm{B}}\left(R^{2}=\right.$ 0.7748, $\left.R=-0.880, P<0.01 ; R^{2}=0.8193, R=-0.905, P<0.01\right)$. Similarly, high negative correlation was observed between $W_{\mathrm{B}}$ and protein and polysaccharide contents in the LB-EPS $\left(R^{2}=0.8310\right.$, $\left.R=-0.912, P<0.01 ; R^{2}=0.7818, R=-0.884, P<0.01\right)$. Compared with S-EPS and LB-EPS, the positive correlation $(R=$ $0.976, P<0.01$ and $R=0.987, P<0.01$ ) between bound water and protein, and polysaccharide contents in the TB-EPS was more significant $\left(R^{2}=0.9745 ; R^{2}=0.9521\right)$. Similar results were also revealed by Jin et al. ${ }^{6}{ }^{6} W_{\mathrm{B}}$ had a significant positive correlation with the amount of protein and carbohydrate measured in the TB-EPS.

A correlation analysis demonstrated that S-EPS, LB-EPS, and TB-EPS had strong correlations with bound water. The increase in protein and polysaccharide contents in the S-EPS and LB-EPS and their decrease in the TB-EPS could cause a drop of $W_{\mathrm{B}}$. TBEPS accounts for over $85 \%$ of total EPS in the original sludge. The decrease in protein and polysaccharide contents in TB-EPS led to the increase in EPS contents in the LB-EPS and S-EPS under DDBAC conditioning (Fig. 3). Thus, it can be inferred that the bound water trapped in the TB-EPS and the TB-EPS content was the main factor that influenced $W_{\mathrm{B}}$. These findings were similar to a research reported by Dursun, ${ }^{35}$ who observed that EPS could result in a fairly tenacious retention of water within the sludge. Song et al. ${ }^{36}$ also draw the conclusion that high contents of EPS, especially insoluble EPS, were responsible for the relatively higher $W_{\mathrm{B}}$. Yuan et al. ${ }^{30}$ observed a similar phenomenon, showing that TB-EPS may be responsible for the water retention of sludge and could highly influence the sludge dewatering and drying.
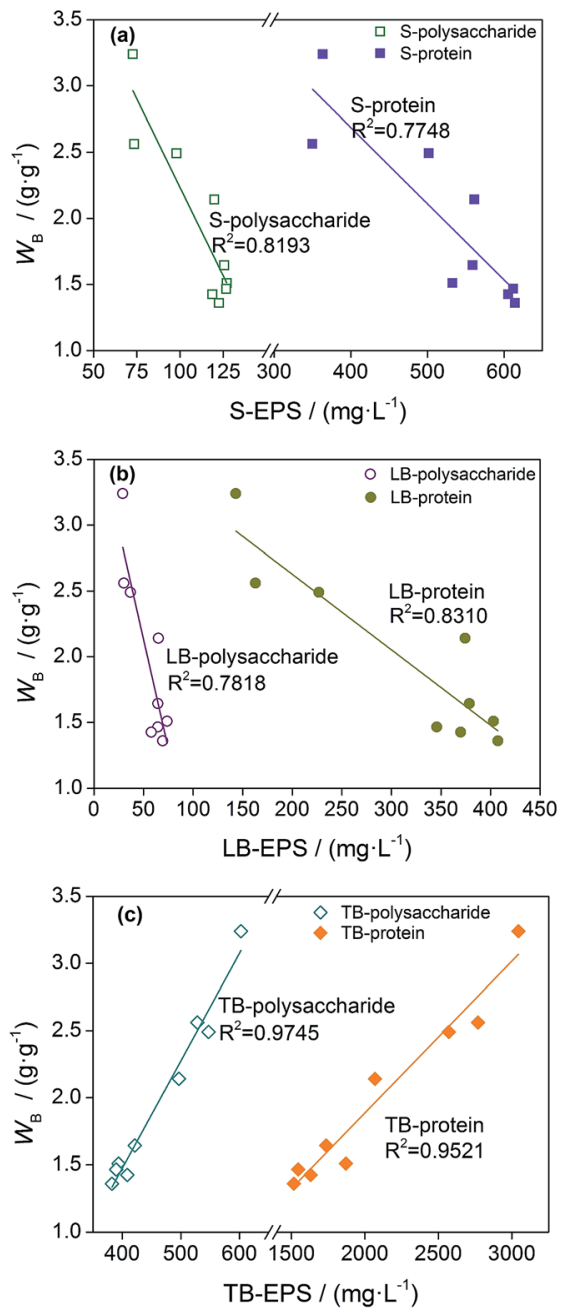

Fig. 5 Correlation between protein and polysaccharide contents in EPS layers and $W_{B}$ : (a) correlation between S-EPS and $W_{B}$; (b) correlation between LB-EPS and $W_{B}$; (c) correlation between TB-EPS and $W_{\mathrm{B}}$.

\subsection{Change of organic functional groups in S-EPS}

The FTIR spectra of S-EPS extracted from sludge under conditioning with different DDBAC dosages are shown in Fig. 6. S-EPS in the original sludge exhibit several obvious absorption peaks at $3394 \mathrm{~cm}^{-1}, 2926 \mathrm{~cm}^{-1}, 1636 \mathrm{~cm}^{-1}, 1428$ $\mathrm{cm}^{-1}$, and $1108 \mathrm{~cm}^{-1}$. Absorption maxima near $3340 \mathrm{~cm}^{-1}$

Table 2 Pearson correlation coefficients between protein and polysaccharide contents in EPS layers and $W_{B}$

\begin{tabular}{lll}
\hline Composition & EPS layer & $W_{\mathrm{B}}$ \\
\hline Protein & S-EPS & $-0.880^{a}$ \\
& LB-EPS & $-0.912^{a}$ \\
Polysaccharide & TB-EPS & $0.976^{a}$ \\
& S-EPS & $-0.905^{a}$ \\
& LB-EPS & $-0.884^{a}$ \\
& TB-EPS & $0.987^{a}$
\end{tabular}




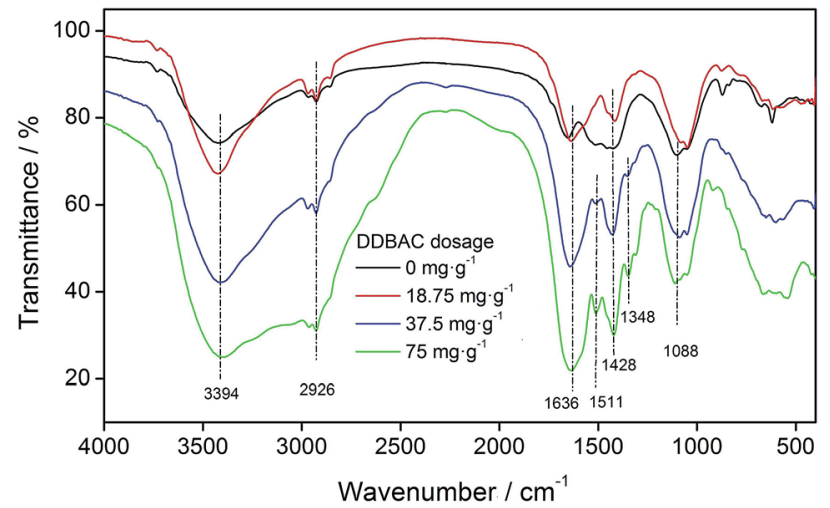

Fig. 6 FTIR spectra of S-EPS in sludge.

(H-bound $\mathrm{OH}$ in polysaccharides), $2950 \mathrm{~cm}^{-1}$ (aliphatic $\mathrm{C}-\mathrm{H}$ stretching), $1600 \mathrm{~cm}^{-1}$ to $1660 \mathrm{~cm}^{-1}(\mathrm{C}=\mathrm{O}$ in amides, protein peptide bond), $1420 \mathrm{~cm}^{-1}$ ( $\mathrm{C}=\mathrm{O}$ in carboxyl groups), and 1090 $\mathrm{cm}^{-1}$ (C-O-C stretching of polysaccharides) had been reported in other studies. ${ }^{37-39}$ In all the spectra we observed that the broad band at $3394 \mathrm{~cm}^{-1}$ confirmed the presence of abundant $\mathrm{OH}$ groups, which would indicate that S-EPS may contain polysaccharides. ${ }^{39}$ The absorption band in the region of 2926 $\mathrm{cm}^{-1}$ corresponded to the stretching vibrations of aliphatic $\mathrm{C}-\mathrm{H}$ bonds that show the existence of lipids. The presence of amides I was shown by a strong absorbance at $1636 \mathrm{~cm}^{-1}$, corresponding to protein in the S-EPS. ${ }^{37}$ The weak absorption band at $1428 \mathrm{~cm}^{-1}$ indicated the existence of carboxyl groups because of the stretching vibration of $\mathrm{C}=\mathrm{O}^{37}$ The strong absorption band at $1088 \mathrm{~cm}^{-1}$ was due to the stretching of $\mathrm{C}-\mathrm{O}-\mathrm{C}$, which demonstrated the existence of polysaccharide in S-EPS. ${ }^{38}$

Peak intensities at $3394 \mathrm{~cm}^{-1}, 1636 \mathrm{~cm}^{-1}, 1428 \mathrm{~cm}^{-1}, 1108$ $\mathrm{cm}^{-1}$ significantly enhanced after DDBAC conditioning. The increase of amides and polysaccharides (at $3394 \mathrm{~cm}^{-1}, 1636$ $\mathrm{cm}^{-1}$, and $1108 \mathrm{~cm}^{-1}$ ) indicated that a large amount of protein and polysaccharides turned from insoluble into dissolved state under DDBAC conditioning, and could be found in the sludge liquid phase. This observation was in accordance with the decrease in TB-EPS content and the increase in LB-EPS in earlier results. A significant enhancement in peak intensity at $1428 \mathrm{~cm}^{-1}$ indicated that the most possible reason of carboxyl increment was that the hydrolysis of TB-EPS and LB-EPS generated a certain amount of carboxylic acid, carboxylic acid salts, and other small organic molecules. When the DDBAC dosage was more than $37.5 \mathrm{mg} \mathrm{g}^{-1}$, two new adsorption bands were observed at $1511 \mathrm{~cm}^{-1}$ and $1348 \mathrm{~cm}^{-1}$. According to previous studies, the absorption band at 1511 $\mathrm{cm}^{-1}$ was likely the consequence of the vibrations of amides II and/or of $\mathrm{N}-\mathrm{H}$ bonds. ${ }^{40,41}$ It indicated that more new types of insoluble protein in TB-EPS and LB-EPS turned into dissolved ones in S-EPS, and bound water was released in a high degree. A weak band was observed at $1348 \mathrm{~cm}^{-1}$, which was related to $\mathrm{C}=\mathrm{O}$ in carboxylic acid and $\mathrm{H}$-bound $\mathrm{OH}$ in alcohols and phenols. This finding indicated that EPS had been hydrolyzed in some degree.

\subsection{Analysis of EPS hydrolysis under the conditioning of surfactant DDBAC}

The liquid chromatogram of organics in the sludge supernatant is shown in Fig. 7(a), and the changes in short-chain fatty acids (formic acid, acetic acid, and propionic acid in this study) contents are reported in Fig. 7(b). The sequence of chromatography peaks in the reversed-phase highperformance liquid chromatography was relevant to the molecular weight and polarity of the organics. Generally, the peak of organics that had small molecular weight and strong polarity appear earlier than those that have a significantly larger molecular weight, high polymerization degree, and strong polarity. Peak intensity was positively in accordance with the amount of organic content. In this study, the retention times of formic acid, acetic acid, and propionic acid peak were $5.73 \mathrm{~min}, 8.73 \mathrm{~min}$, and $18.32 \mathrm{~min}$, respectively. According to previous studies, these organics that had retention times between $5 \mathrm{~min}$ and $22.5 \mathrm{~min}$ were small molecular organics. In Fig. 7(a), the number and intensity of chromatographic peaks significantly increased after the DDBAC conditioning, which demonstrated an increase in the species and contents of small molecular organics. Hydrolysis was demonstrated by short-chain fatty acids concentration in the sludge supernatant. The three organic acids, particularly formic acid and acetic acid, significantly increased along with the increase in DDBAC dosages, which indicated that the DDBAC could improve the hydrolysis of organics in sludge (Fig. 7(b)). Luo et al. ${ }^{42}$ observed that surfactants can be used to enhance the hydrolysis of sludge and to increase the short-chain fatty
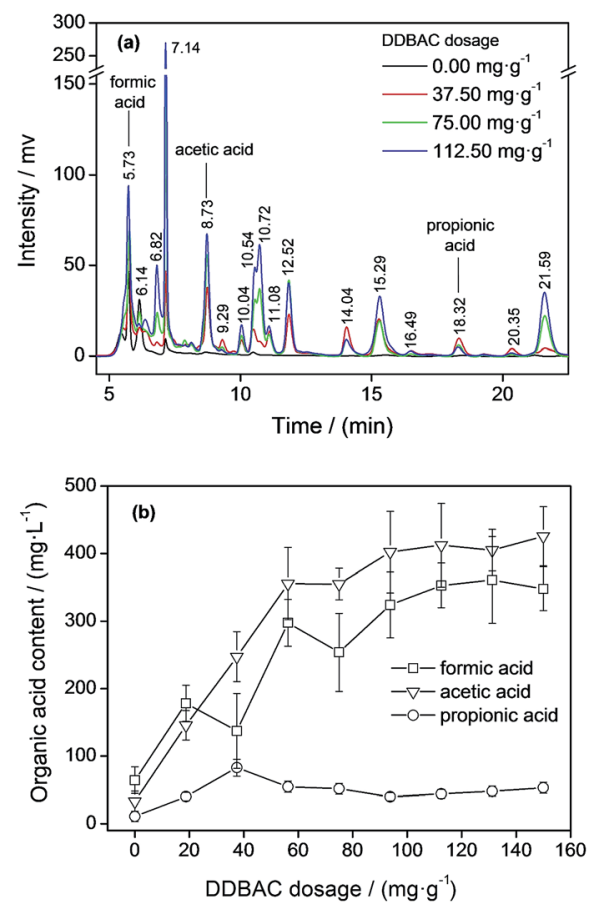

Fig. 7 EPS hydrolysis under the conditioning of DDBAC: (a) liquid chromatogram of organics in sludge supernatant, (b) organic acid contents in sludge supernatant. 
acids concentration. Furthermore, Huang et al. ${ }^{33}$ pointed out that the high surface activity of the surfactant may be the fundamental reason of the enhancement of organic matters solubilization and hydrolysis, which was beneficial for small molecular organics production. Chen et al. ${ }^{43}$ raised another reason, he reported that the surfactant caused changes in protein structure and benefited protein hydrolysis. Therefore, the surfactant DDBAC was not only able to dissolve and desquamate the combined extracellular polymeric substance in sludge flocs, but also boost macromolecular organic compounds, such as protein and polysaccharide in EPS, hydrolyzing into small molecular organics, which had a beneficial effect on the release of bound water in sludge.

\section{Conclusions}

Surfactant DDBAC could effectively reduce $W_{\mathrm{B}}$ and improve the dewatering performance of sludge. When DDBAC dosage was $75 \mathrm{mg} \mathrm{g}^{-1}, W_{\mathrm{B}}$ dropped from $3.24 \mathrm{~g} \mathrm{~g}^{-1}$ to $1.64 \mathrm{~g} \mathrm{~g}^{-1}$, a $49.38 \%$ decrease was observed. Moreover, $W_{\mathrm{C}}$ decreased to $66.61 \%$.

The binding effect of sludge flocs on TB-EPS and LB-EPS layers was weakened by adding DDBAC, which enhanced the solubility of TB-/LB-EPS. Therefore, parts of TB-EPS turned into LB-EPS and S-EPS, and parts of LB-EPS turned into S-EPS.

The quantities of organic functional groups and small molecular organics increased obviously in the sludge supernatant, which showed that EPS was hydrolyzed by DDBAC as well.

The amount of TB-EPS was more than $85 \%$ in total EPS in sludge. Protein and polysaccharide contents in TB-EPS had significant positive correlation with $W_{\mathrm{B}}$. TB-EPS were considered to be the main factor influencing $W_{\mathrm{B}}$.

\section{Acknowledgements}

This work was funded by the National Natural Science Foundation of China (51104009), Beijing Nova Program (Z111106054511043), Beijing outstanding talent nurture and funding scheme (2012D009006000003), Fundamental Research Funds for the Central Universities (FRF-TP-12-011B), and Kunming Science and Technology Program (2012-02-09-A-G-020001).

\section{Notes and references}

1 M. Citeau, O. Larue and E. Vorobiev, Water Res., 2006, 45, 2167-2180.

2 M. Tokumura, M. Sekine, M. Yoshinari, H. T. Znad and Y. Kawase, Process Biochem., 2007, 42, 627-633.

3 X. Li and S. Yang, Water Res., 2007, 41, 1022-1030.

4 P. A. Vesilind and C. J. Martel, J. Environ. Eng., 1990, 116, 854-862.

5 P. A. Vesilind, Water Environ. Res., 1994, 66, 4-11.

6 B. Jin, B. M. Wilén and P. Lant, Chem. Eng. J., 2004, 98, 115126.

7 G. H. Yu, P. J. He, L. M. Shao and P. P. He, Environ. Sci. Technol., 2008, 42, 7944-7949.
8 V. Urbain, J. Block and J. Manem, Water Res., 1993, 27, 829838.

9 K. Keiding, L. Wybrandt and P. Nielsen, Water Sci. Technol., 2001, 43, 17-23.

10 D. Mowla, H. N. Tran and D. G. Allen, Biomass Bioenergy, 2013, 58, 365-378.

11 A. Ding, F. Qu, H. Liang, S. Guo, Y. Ren, G. Xu and G. Li, RSC Adv., 2014, 47, 24762-24768.

12 X. Yin, P. Han, X. Lu and Y. Wang, Ultrason. Sonochem., 2004, 11, 337-348.

13 M. F. Dignac, V. Urbain, D. Rybacki, A. Bruchet, D. Snidaro and P. Scribe, Water Sci. Technol., 1998, 38, 45-53.

14 J. I. Houghton and T. Stephenson, Water Res., 2002, 36, 3620-3628.

15 T. L. Poxon and J. L. Darby, Water Res., 1997, 31, 749-758.

16 Y. G. Chen, Y. S. Chen and G. Gu, Chem. Eng. J., 2004, 99, 137-143.

17 S. Chitikel and S. K. Dentel, Water Environ. Res., 1998, 70, 1062-1069.

18 C. Chu, D. Lee and C. Huang, J. Colloid Interface Sci., 1998, 206, 181-188.

19 C. Huang and G. Fu, Water Sci. Technol., 2000, 41, 17-22.

20 H. Yuan, N. Zhu and F. Song, Bioresour. Technol., 2011, 102, 2308-2315.

21 J. Vaxelaire and P. Cézac, Water Res., 2004, 38, 2215-2230.

22 G. H. Yu, P. J. He, L. M. Shao and D. J. Lee, Appl. Microbiol. Biotechnol., 2007, 77, 605-612.

23 O. Classics Lowry, N. Rosebrough, A. Farr and R. Randall, J. Biol. Chem., 1951, 193, 265-275.

24 P. Riesz, D. Berdahl and C. Christman, Environ. Health Perspect., 1985, 64, 233-252.

25 F. Colin and S. Gazbar, Water Res., 1995, 29, 2000-2005.

26 L. F. Wang, D. Q. He, Z. H. Tong, W. W. Li and H. Q. Yu, Biochem. Eng. J., 2014, 91, 174-178.

27 X. Feng, J. Deng, H. Lei, T. Bai, Q. Fan and Z. Li, Bioresour. Technol., 2009, 100, 1074-1081.

28 Y. Liu and H. H. Fang, Crit. Rev. Environ. Sci. Technol., 2003, 33, 237-273.

29 B. M. Wilén, B. Jin and P. Lant, Water Res., 2003, 37, 36323645 .

30 D. Yuan and Y. Wang, Biochem. Eng. J., 2013, 77, 208-213.

31 H. Wang, H. Deng, L. Ma and L. Ge, Carbohydr. Polym., 2013, 92, 510-515.

32 S. Kavitha, C. Jayashree, S. Adish Kumar, I. T. Yeom and J. Rajesh Banu, Bioresour. Technol., 2014, 168, 159-166.

33 X. F. Huang, C. M. Shen, J. Liu and L. J. Lu, Chem. Eng. J., 2015, 264, 280-290.

34 W. J. Lv, Y. F. Hu, B. C. Zhan, Z. H. Liu, Y. Z. Shang, H. Y. Wang and H. L. Liu, Acta Phys.-Chim. Sin., 2014, 30, 811-820.

35 D. Dursun, Ph.D. thesis, University of Delaware, 2007.

36 Y. W. Song, G. Y. Zheng, M. B. Huo, B. W. Zhao and L. X. Zhou, Environ. Technol., 2014, 35, 2538-2545.

37 A. R. Badireddy, S. Chellam, P. L. Gassman, M. H. Engelhard, A. S. Lea and K. M. Rosso, Water Res., 2010, 44, 4505-4516. 38 L. El Fels, M. Zamama, A. El Asli and M. Hafidi, Int. Biodeterior. Biodegrad., 2014, 87, 128-137. 
39 L. Zhu, H. Y. Qi, M. L. Lv, Y. Kong, Y. W. Yu and X. Y. Xu, Bioresour. Technol., 2012, 124, 455-459.

40 A. Barth and C. Zscherp, Q. Rev. Biophys., 2002, 35, 369-430.

41 M. Mecozzi and E. Pietrantonio, Mar. Chem., 2006, 101, 2739.
42 K. Luo, Q. Yang, J. Yu, X. M. Li, G. J. Yang, B. X. Xie, F. Yang, W. Zheng and G. M. Zeng, Bioresour. Technol., 2011, 102, 7103-7110.

43 Y. G. Chen, K. Liu, Y. L. Su, X. Zheng and Q. Wang, Bioresour. Technol., 2013, 140, 97-102. 